\title{
A IMPORTÂNCIA DO MERCADO INSTITUCIONAL PARA AGRICULTURA FAMILIAR: UMA BREVE ANÁLISE DO PAA NO ASSENTAMENTO GALVÃO CANTANHEDE NO MUNICÍPIO DE CANTANHEDE-MA ${ }^{1}$
}

\section{THE IMPORTANCE OF INSTITUTIONAL MARKET TO FAMILY FARMING: A BRIEF ANALYSIS OF PAA IN THE GALVÃO CANTANHEDE SETTLEMENT IN THE CANTANHEDE-MA MUNICIPALITY}

\author{
Jéssica Neves MENDES ${ }^{2}$ \\ Igor Breno Barbosa de SOUSA ${ }^{3}$ \\ José Sampaio de MATTOS JUNIOR ${ }^{4}$
}

\begin{abstract}
Resumo: O presente artigo tem como proposta analisar o Programa de Aquisição de Alimentos (PAA) no Assentamento Galvão Cantanhede no município de Cantanhede - MA. O PAA foi instituído em 2003 e tem como ideia principal garantir o acesso aos alimentos em quantidade e regularidade necessárias às populações em situação de insegurança alimentar e nutricional e promover a inclusão social no campo por meio do fortalecimento da agricultura familiar. Além disso, a pesquisa pretende identificar as modalidades do PAA acessadas pelos assentados do PA Galvão Cantanhede e verificar as estratégias utilizadas pelos assentados para acessar o Programa de Aquisição de Alimentos no município.
\end{abstract}

Palavras-Chaves: Agriculta familiar; Galvão Cantanhede; PAA.

\begin{abstract}
The purpose of this article is to analyze the Food Acquisition Program (PAA) in the Galvão Cantanhede settlement in the Cantanhede - MA municipality. The PAA was established in 2003 and it has as main idea to guaranty the access to foods in quantity and regularity necessaries to population in situation of insecurity alimentary and nutritional and to promote the social inclusion in field through the empowerment family farming. In addition, the research intends to identify the PAA modalities accessed by settlers of PA Galvão Cantanhede, and check the strategies used by the settlers to access the Food Acquisition Program in municipality.
\end{abstract}

Keywords: Family farming; Galvão Cantanhede; PAA.

\footnotetext{
${ }^{1} \mathrm{O}$ presente artigo é resultado do projeto de pesquisa de Iniciação Científica financiado pela Fundação de Amparo à Pesquisa e ao Desenvolvimento Científico e Tecnológico do Maranhão.

${ }^{2}$ Mestranda do Programa de Pós-graduação em Desenvolvimento Socioespacial e Regional e Graduada em Geografia, ambos pela Universidade Estadual do Maranhão (UEMA), e integrante do Grupo de Estudos de Dinâmicas Territoriais (GEDITE). E-mail: jessicanevesmendes@ outlook.com.

${ }^{3}$ Professor do curso de Geografia no Núcleo de Tecnologias para Educação (UEMAnet) da Universidade Estadual do Maranhão e do Centro de Referência em Formação e Educação a Distância no curso de Especialização em Geoprocessamento Aplicado no Instituto Federal do Norte de Minas Gerais (IFNMG Diamantina). Mestre em Desenvolvimento Socioespacial e Regional e Graduado em Geografia, ambos pela Universidade Estadual do Maranhão, e integrante do Grupo de Estudos de Dinâmicas Territoriais (GEDITE). Email: iggor_breno@hotmail.com.

${ }^{4}$ Doutor em Geografia. Docente do curso de Geografia, dos Programas de Pós-graduação em Desenvolvimento Socioespacial e Regional e de Geografia na Universidade Estadual do Maranhão (UEMA). E-mail: sampaio.uema@gmail.com.
} 


\section{Introdução}

A partir da década de 70, a elaboração das políticas de planejamento no Brasil tem em seus debates o desenvolvimento territorial, que recebe progressivamente mais espaço nas pautas de discussão acerca de políticas e, consequentemente, sobre os programas de governo nas esferas federais, estaduais e municipais, a serem aplicados. De acordo com Silva (2013), a década de 80, motivada pela busca da liberdade civil frente a um Estado autoritário, constituído a partir de 1964, foi marcada por mudanças no cenário político, como a definição de uma nova atuação do Estado. Com a Constituição Federal de 1988, passou-se a ser estabelecido um compromisso com a questão regional, cabendo ao Governo Federal estabelecer metas a fim de reduzir as desigualdades regionais, assim, foram implantados programas de desenvolvimento nas regiões Norte, Sul, Nordeste e Centro-Oeste.

Entretanto, Silva (2013) destaca a questão do desenvolvimento territorial, uma vez que essa mostrou-se cada vez mais importante no planejamento de um governo, principalmente nas discussões sobre estratégias de políticas públicas voltadas ao campo. Como exemplo disso, tem-se a criação da Secretaria de Desenvolvimento Territorial (SDT) em 2003 pelo Governo Federal, na perspectiva de integrar os territórios nacionais, estimulando, assim, o desenvolvimento territorial. Desta forma, o território torna-se um espaço de construção de projetos a serem implantados visando diminuir as desigualdades regionais, sobretudo, em regiões que sofrem com a falta de políticas públicas, as quais são consideradas prioritárias pelo Ministério do Desenvolvimento Agrário (MDA) ${ }^{5}$.

No campo dessas experiências e nos diferentes territórios, surgiram novas dinâmicas de desenvolvimento com o objetivo de gerar novas oportunidades à população dos territórios rurais, para isto, foram criados programas auxiliares a partir do Plano Territorial de Desenvolvimento Rural Sustentável (PTDRS), tais como: o Programa Nacional de Desenvolvimento Sustentável de Territórios Rurais (PRONAT), Programas Territórios da Cidadania (PTC), Consórcios de Segurança Alimentar e Desenvolvimento Local (CONSAD) e o Programa de Aquisição de Alimentos (PAA), foco deste artigo.

O PAA foi instituído pelo artigo 19 da Lei $n^{\circ}$ 10.696, de 2 de julho de 2003 e regulamentado pelo Decreto $n^{\circ} 7.775$, de 4 de julho de 2012. Além disso, esse programa constituiu-se em uma das ações abrigadas pelo Sistema Nacional de Segurança Alimentar e

\footnotetext{
${ }^{5}$ O Ministério do Desenvolvimento Agrário foi extinto por meio do decreto $\mathrm{n}^{\mathrm{o}} 8.865$, em 29 de setembro de 2016, suas atribuições estão subordinadas na Secretaria de Agricultura Familiar e Cooperativismo do Ministério da Agricultura, Pesca e Abastecimento.
} 
Nutricional (SISAN), congregada pelo Programa Fome Zero (PFZ). O PAA possui como objetivo: "incentivar a agricultura familiar por meio da inclusão socioeconômica; incentivar o consumo e valorização dos alimentos produzidos pela agricultura familiar; além de promover $\mathrm{o}$ acesso à alimentação em quantidade e qualidade às pessoas em situação de insegurança alimentar e nutricional" (CONAB, 2018. p. 52).

Assim, o ano de 2003 marcou a introdução de novas institucionalidades nos territórios por meio da implantação de várias políticas de desenvolvimento territorial. No entanto, entendemos que mesmo essas políticas de desenvolvimento territorial terem sido pensadas e estruturadas, prioritariamente, para a consolidação da agricultura familiar, elas continuam a apresentar contradições nas relações de poder, gerando conflitos e desarticulações entre as esferas municipal, estadual e federal.

A partir disso, por meio do estudo de políticas públicas voltadas para o campo, buscamos, por intermédio deste artigo, analisar o PAA no assentamento Galvão Cantanhede localizado no município de Cantanhede - MA. Vale ressaltar que o município de Cantanhede está localizado na mesorregião Norte Maranhense e, de acordo com dados do Instituto Brasileiro de Geografia e Estatística (2010), abrange uma área de 773,010 km² para uma população de 20.448 habitantes, sendo 12.959 de pessoas residindo na zona urbana e 7.489 de pessoas residindo na zona rural.

A presença de agricultores familiares é predominante no município de Cantanhede, bem como em todo o estado do Maranhão. Também, uma das características nessa região é a prática da "roça de toco", exercida pelas práticas da agricultura tradicional, a qual se constitui na queimação da vegetação do terreno para limpá-lo. Nesse município, localiza-se o assentamento Galvão Cantanhede (Mapa 1) e este possui uma área de 5.540,58ha, com 295 famílias assentadas, criado a partir de uma desapropriação no dia 20 de dezembro de 1993. 
Mapa 1 - Localização do Assentamento Galvão Cantanhede.

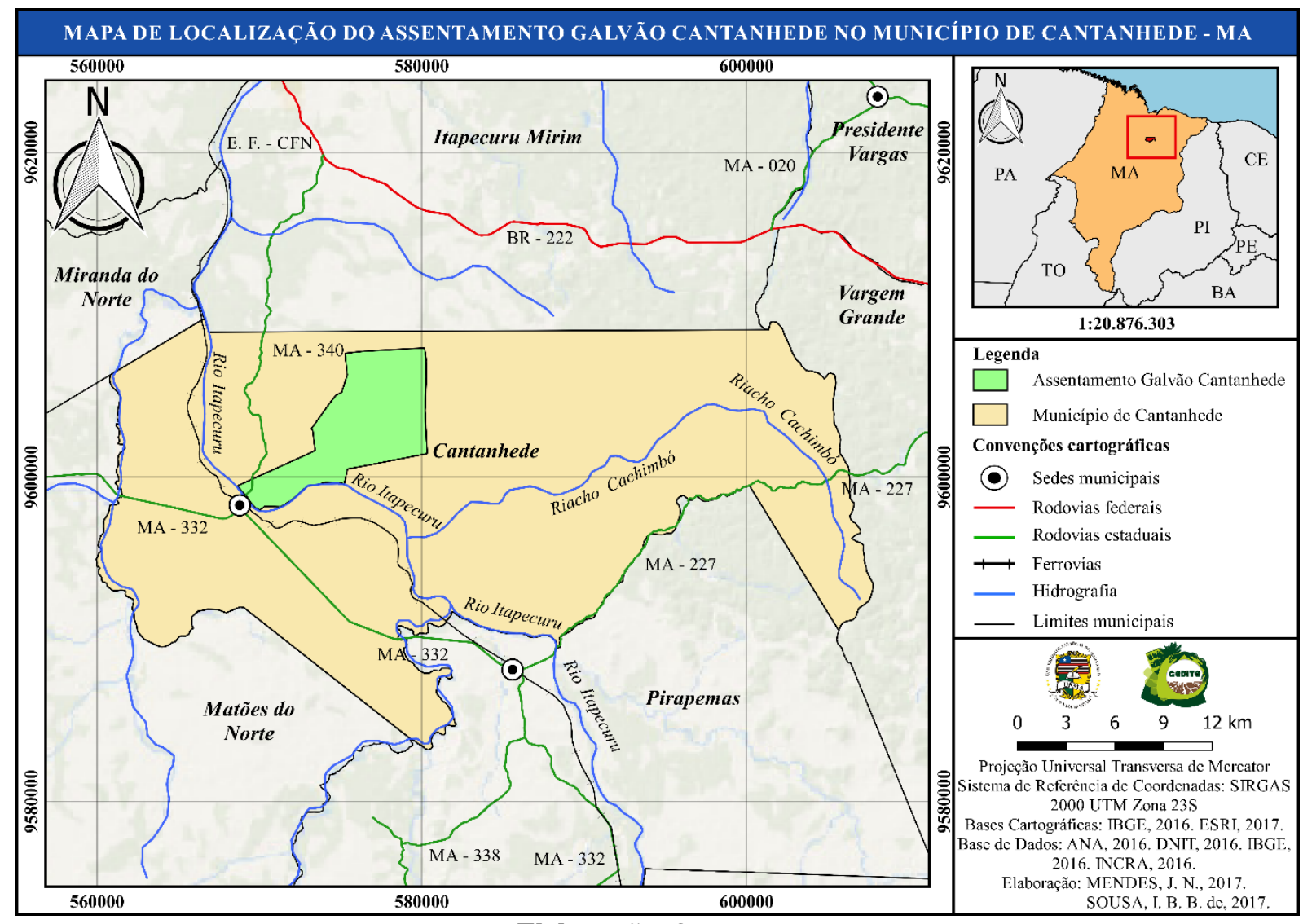

Elaboração: Os autores.

Para a consecução desta pesquisa, estabelecemos o método Materialismo Histórico e Dialético, pois apontamos as correlações de poder existentes e o jogo de forças mediado pelo Estado, assim como levamos em consideração a conjuntura macroeconômica estruturada no âmbito capitalista. Embora políticas como PAA sejam importantes para o incentivo à produção local, os próprios arranjos institucionais regulamentados pelo Estado, que criam formas de ingressar o pequeno produtor no mercado, são os que desarticulam a política frente ao capital desenfreado. Portanto, Marx (2003a, p. 5) aponta que:

[...] na produção social da sua existência, os homens estabelecem relações determinadas, necessárias, independentes de sua vontade, relações de produção que correspondem a um determinado grau de desenvolvimento das forças produtivas materiais. O conjunto destas relações de produção constitui a estrutura econômica da sociedade, a base concreta sobre a qual se eleva uma superestrutura jurídica e política e à qual correspondem determinadas formas de consciência social.

Assim, Marx (1998) compreende que a sociedade civil é fundamento de toda a história e, para representá-la, é necessário compreender suas ações e explicar dentro de um conjunto 
de produções teóricas as formas de consciência, a partir da gênese de suas produções, permitindo, por conseguinte, representar o objeto na sua totalidade.

Para confecção do artigo, foi realizada leitura de referenciais bibliográficos envolvendo autores que promovem discussões acerca do Território, como: Haesbaert (2007), Raffestin (1993), e Saquet (2015); Políticas Territoriais, Plano Nacional de Reforma Agrária, desenvolvimento territorial e acerca do nosso objeto de estudo elencamos: Grisa e Porto (2015), Saron, Neves Neto e Hespanhol (2017), Veloso (2017), e Hentz e Hespanhol (2019).

No que tange aos dados secundários, estes que foram primordiais para nosso estudo, consultamos os resultados obtidos do Censo Demográfico de 2010 aplicados pelo IBGE. Posteriormente, no âmbito nacional, coletamos os dados obtidos pelo Compêndio de Estudos da Companhia Nacional de Abastecimento (CONAB) sobre o PAA, além da aquisição de dados sobre o PAA pelo Portal da Transparência, fornecidos pelo Ministério da Cidadania e CONAB, nos planos estadual e municipal, juntamente com Secretaria de Estado da Agricultura Familiar (SAF). Assim, obtivemos informações acerca do número de repasses financeiros, quantitativo de beneficiários consumidores e fornecedores, produtos cultivados e entidades recebedoras do PAA no município de Cantanhede - MA.

Além disso, ressaltamos a visita e a observação em campo no assentamento Galvão Cantanhede, bem como a aplicação de 15 questionários com os beneficiários do PAA no assentamento, aplicação de entrevistas estruturadas com o secretário de agricultura Sebastião Brandão do município de Cantanhede e com as presidentas das associações da Agricultura Familiar e das Quebradeiras de Coco, respectivamente, Maria José Pereira Paiva e Castorina Neres Gomes. Isso foi feito com a finalidade de coletar informações sobre a composição dos beneficiários do PAA. A partir da aquisição dos dados necessários para nossas análises, utilizamos os métodos estatísticos por meio do software Excel, assim como, para as representações cartográficas, usamos aporte do software de Sistema de Informações Geográficas (SIG), o QGIS 3.4.

Por meio do processamento desses dados geográficos e convencionais, combinamos as nossas análises e interpretações à construção do texto deste artigo. 


\section{TERRITÓRIO: entre a discussão teórica, concepção governamental e sua utilização}

Para compreendermos como se dá o processo de execução dos programas do Governo Federal, é importante se fundamentar em alguns conceitos de território, e desse modo analisar como este conceito foi adotado nas Políticas Públicas do Governo Federal e na área de estudo no assentamento Galvão Cantanhede no município de Cantanhede - MA.

Desse modo, resgatamos a forte heterogeneidade das macrorregiões brasileiras deixadas como legado das políticas de desenvolvimento regional. Isso revelou a necessidade de novas escalas de planejamento, incluindo a abordagem territorial como nova norteadora das políticas a serem aplicadas. Desta forma, lembramos Raffestin (1993), o qual compreende que o espaço é anterior ao território, sendo este o resultado de uma ação conduzida por um agente sintagmático, o qual, ao se apropriar de um espaço, "territorializa" o mesmo. Retomando as reflexões de Ratzel e Raffestin, para Souza (1995, p. 78), o território "é fundamentalmente um espaço definido e delimitado por e partir de relações de poder". O autor salienta que o território surge na Geografia Política como um espaço concreto e que é apropriado e ocupado por um grupo social, assim sendo:

A ocupação do território é vista como algo gerador de raízes e identidade: um grupo não pode mais ser compreendido sem o seu território, no sentido de que a identidade sócio-cultural das pessoas estaria inarredavelmente ligada aos atributos do espaço concreto (natureza, patrimônio arquitetônico, "paisagem"). (SOUZA, 1995, p. 84).

Nessa abordagem, o território, além de político, é também cultural, tendo em vista que os grupos sociais estabelecem relações de poder. Por sua vez, a dimensão política, a que envolve relações de poder, é a condição de existência do território, uma vez que esta dimensão é o momento da materialização de alguma prática espacial. Nessa perspectiva, Medeiros (2008) elenca o território como um espaço de identidade e ambos (espaço e território) não podem ser dissociados, pois o espaço é a condição de existência do território e o território é a condição para que o espaço se humanize.

Não obstante, o território para Haesbaert (2007) trata-se de uma construção histórica e, portanto, social, a partir das relações de poder (concreto e simbólico) que envolvem concomitantemente sociedade e espaço geográfico (este que também é sempre, de alguma forma, natureza). Embora exista uma diversidade de discussões sobre o conceito de território, as propostas teóricas que possuem maior ressonância estão elaboradas a partir da perspectiva 
da Geografia Política, a qual apresenta relações de poder, apropriação, dominação e até mesmo disputas.

Para tanto, diante das diferentes interpretações acerca do território, que são fundamentais para enriquecer nossa reflexão, é importante destacar qual concepção norteará a orientação teórica-metodológica da nossa pesquisa. Assim, tomemos o conceito de Saquet (2015) que define o território como:

[...] produto das relações sociedade-natureza e condição para a reprodução social; campo de poder que envolve edificações e relações sociais (econômicas-políticas-culturais-ambientais) historicamente determinadas. O território é resultado e determinante da reprodução da relação sociedadenatureza e da concomitante territorialização. Os territórios são produzidos espacio-temporalmente pelo exercício do poder por determinado grupo ou classe social e por suas respectivas territorialidades cotidianas. A (i)materialidade está tanto no resultado-produto como na condição-devir (SAQUET, 2015, p. 45).

As territorialidades, como refere-se o autor acima, são determinantes para cada território e influenciam a sua reprodução na relação espaço-tempo. Portanto, as forças sociais efetivam-se no território e com o espaço geográfico cristalizando as territorialidades econômicas e/ou políticas, e/ou culturais, e/ou ambientais, que constroem sentido ao território. Por consequência, constitui-se a agricultura familiar pela apropriação do território, visando sua permanência, a qual carrega consigo relações sociais perpetuadas em suas gerações. Por isso, entendemos que nas discussões propostas, mesmo que o assentamento seja pensado e estruturado para a consolidação da agricultura familiar, o território tem relações de poder, conflitos de interesses e não é um espaço homogêneo.

Entretanto, a concepção do Governo Federal revela que para a SDT, as políticas territoriais são importantes para o ordenamento territorial, assim como servem para o processo de complemento para políticas de descentralização. Diante disso, a SDT considera território como:

Um espaço físico, geograficamente definido, geralmente contínuo, compreendendo a cidade e o campo, caracterizado por critérios multidimensionais - tais como o ambiente, a economia, a sociedade, a cultura, a política e as instituições - e uma população com grupos sociais relativamente distintos, que se relacionam interna e externamente por meio de processos específicos, onde se pode distinguir um ou mais elementos que indicam identidade e coesão social, cultural e territorial (MDA/SDT, 2005, p. 11). 
Nessa perspectiva, compreende-se que o conceito de território usado pelo MDA não está diretamente ligado às abordagens usadas por diversos autores na academia, o qual na Geografia este conceito é mais amplo. Por isso Fernandes (2005, p. 5) propõe que:

O território tem que ser compreendido na sua multidimensionalidade, contudo os elementos da natureza e os espaços produzidos pelas relações sociais que o produz e o mantêm a partir de uma forma de poder e sua existência e destruição são determinados pelas relações oficiais existente sendo um espaço de liberdade, de dominação de expropriação e resistência.

Nesse contexto, o Estado apropria-se da categoria geográfica do Território e o emprega como uma unidade de referência das suas ações políticas e o seu enfoque torna-se um modo de ação que valoriza os aspectos políticos e culturais das comunidades e/ou atores sociais. Com isto, governança local e participação social também se tornam atributos do desenvolvimento territorial.

No entanto, se compararmos a noção de Território para com a visão do Estado, este último difere-se da discussão proposta por vários autores acadêmicos, haja vista que isenta as relações sociais, as quais dão sentido a construção do Território e, por consequência, limita-o somente a um espaço geográfico. Assim, o Território é apropriado e coisificado pelo Estado, passando a ser como um eixo estruturante para as políticas públicas, sobretudo, as voltadas para o desenvolvimento rural no Brasil em meados da década de 90, caracterizado pela abordagem territorial, a qual tem por referência o desenvolvimento local. Ou seja, cria-se uma proposta de incorporar às políticas de desenvolvimento com as especificidades de cada território. Nesse contexto, são criadas várias institucionalidades na perspectiva de estimular investimentos e estabelecer que os próprios atores locais sejam protagonistas na elaboração de projetos territoriais financiados pelo Estado.

Na década de 90 são implantadas uma série de programas voltados para a agricultura familiar, tendo em vista a diminuição da pressão dos trabalhadores e trabalhadoras no campo e sendo delineadas no segundo mandato do governo de Fernando Henrique Cardoso (FHC) (1995-2002), perpassando nos governos petistas de Luís Inácio Lula da Silva (2003-2010) e Dilma Rousseff (2011-2016). Assim, perdurando duas décadas, mas que tiveram seu desmanche a partir de 2016 e isso foi consolidado com a crise estrutural dessas políticas no governo Michel Temer (2016-2018). Já no contexto atual, sofre rupturas e descontinuidades nos primeiros anos do governo ultraliberal de Jair Messias Bolsonaro, momento este em que as políticas territoriais rurais se encontram esquecidas, muito por conta da criação do Ministério de Desenvolvimento Regional. 
Ainda que em determinado período o Território tenha sido coisificado pelo Estado para a intervenção por meio das políticas públicas voltadas para o campo, em meio aos retrocessos -, ele continua sendo visto como um conceito articulador e determinante para a (re)criação de estruturas e formas de resistências que se organizam e se manifestam nos vários desdobramentos sucedidos no campo brasileiro, face às modificações impostas pelo Estado capitalista.

Apesar do Território não estar incluído no planejamento governamental brasileiro, as ações do Estado sempre irão refletir nos territórios, seja de forma desejada para alguns ou de forma indesejada para outros, sobretudo, como tem acontecido para a agricultura familiar, comunidades tradicionais, a exemplo de indígenas e quilombolas, em que a prioridade dialogada na agenda governamental é invertida, dando lugar a disputas territoriais contra grandes investimentos apoiados pelo Estado e pelo grande capital estrangeiro.

\section{AS FAMÍLIAS E O PAA: estrutura e modalidades}

Diante do contexto do processo de redemocratização no final dos anos 80, o desenvolvimento rural entra em debate na sociedade, tendo em vista as críticas ao processo de modernização da agricultura, o qual, dentre as consequências, permeia a concentração fundiária e a expulsão de trabalhadores da terra. Porém, no mesmo período, um marco histórico, a Constituição Federal de 1988, traz novas mudanças nas políticas públicas voltadas para o campo. A partir disso, as políticas públicas que o governo FHC passa a elaborar no seu primeiro mandato serão na perspectiva do desenvolvimento rural, dedicando-se ao financiamento da agricultura familiar, com uma proposta de Reforma Agrária por meio do mercado. Com isso, é criado o Programa Nacional de Fortalecimento da Agricultura Familiar (PRONAF) em 1995, este tem como objetivo principal o fortalecimento da agricultura familiar e permite a articulação de políticas voltadas para o campo, bem como o financiamento dos produtos dos agricultores familiares.

Assim, na gestão do governo Lula, estabelece-se uma série de continuidades no modelo das políticas voltadas para a agricultura familiar, mas que avançam na perspectiva de consolidar o desenvolvimento. Neste contexto, o território torna-se recurso principal como estratégia de descentralização da política do PRONAF, tendo em vista as mudanças de recursos do PRONAF-Infraestrutura para projetos de caráter intermunicipal, deixando, assim, 
de caracterizar-se em uma política setorial ao tentar introduzir os primeiros componentes de uma política de desenvolvimento territorial

Nesse sentido, o território tornou-se base de implementação das políticas públicas tendo como ponto principal a discussão das carências mais urgentes, além da consolidação de identidades e cooperações entre os atores sociais. Nessa conjuntura, as políticas territoriais encontraram-se ancoradas especificamente para a redução da pobreza sistematizadas através das transferências sociais basilares do PFZ, além de outros programas públicos, por exemplo: Luz Para Todos, Educação no Campo, Economia Solidária, Bolsa Família. Resultando, assim, em uma articulação política entre vários ministérios, efeito este que, segundo Sousa (2020), é decorrente das reinvindicações dos movimentos sociais.

Com a amplitude dessa política de desenvolvimento territorial e tendo um dos públicos-alvo desta política a agricultura familiar, o PAA surge como uma das estratégias do PFZ, que teve como objetivo o combate à fome e promoção da segurança alimentar, e incorporou o programa Bolsa Família por meio da transferência de renda para as famílias pobres no Brasil, além do PRONAF com novas linhas de créditos para os agricultores familiares.

Dessa forma, o PAA surgiu com a proposta de canalizar o poder de compra do Estado para adquirir alimentos diretamente da agricultura familiar e, assim, destiná-las às populações em situação de insegurança alimentar e nutricional. Por sua vez, o PAA não se trata de uma ação isolada, pois sua concepção parte da premissa de políticas públicas voltadas para agricultura familiar, bem como para o combate à fome. A inclusão de produtos da agricultura familiar no PAA visa valorizar os alimentos com forte identidade cultural, aliada a partir das compras governamentais via mercado institucional. Em 2008, o programa ganha um reforço na constituição dos mercados institucionais, com base na modalidade para atendimento a alimentação escolar, o qual tem por finalidade garantir o direito de compra dos produtos da agricultura familiar em pelo menos $30 \%$ regido pela Lei $\mathrm{n}^{\circ} 11.947$, de 16/6/2009, por meio do Programa Nacional de Alimentação Escolar (PNAE) já existente desde 1979 (BRASIL, 2009).

Ademais, embora o PFZ tenha contribuído para a saída do Brasil no Mapa da Fome da Organização das Nações Unidas (ONU) em 2014, tal política encontra-se em desestruturação. Tomazini e Leite (2016) apontam alguns fatores que implicaram na crise do PFZ ao longo dos anos, como os arranjos administrativos localizados nas regiões Sul e Sudeste, que contribuíram para a criação de uma concorrência para as políticas sociais, uma vez que o PFZ, 
se direcionava para os problemas das regiões Norte e Nordeste. Outra questão a ser levantada, não se trata meramente de capacidade orçamentária, mas no confronto de ideias no direcionamento do PFZ, pois funcionários ingressantes defendiam a segurança alimentar, enquanto, setores da burocracia federal ligados ao Ministério Extraordinário de Segurança Alimentar e Combate à Fome (MESA), defendiam programas de transferência de renda.

Destarte, dada a estrutura da sociedade brasileira, as políticas de enfretamento à pobreza, por meio de transferência de renda, não têm capacidade de alterar as desigualdades sociais e históricas no país, mesmo que caracterize queda na taxa da pobreza. Entretanto tais políticas têm sido implantadas mais como resposta para a saída da crise capitalista do que como uma ação contra a hegemônica do capitalismo (SILVA, 2017). Dessa forma, programas como o PAA e PNAE, ao longo dos anos, acabaram se expandindo como principais políticas relacionadas ao combate à fome e à insegurança alimentar. Apesar das mudanças de governos, estes programas ainda permanecem atualmente, mesmo com alterações em suas estruturas, como políticas centrais na promoção do direito à alimentação.

O PAA tem como proposta a compra pública de produtos de agricultores familiares a preços estabelecidos pela CONAB para a doação, merenda escolar ou formação de estoques. O objetivo central do programa é o fortalecimento tanto da agricultura familiar, comercialização e produção para autoconsumo da população em estado de insegurança alimentar e de fome no município. Dentre os beneficiários fornecedores dos alimentos estão: os agricultores familiares, assentados da reforma agrária, silvicultores, aquicultores, extrativistas, pescadores artesanais, indígenas, integrantes de comunidades remanescentes de quilombos rurais e demais povos e comunidades tradicionais. Quanto aos beneficiários consumidores dos alimentos, estes são os indivíduos em situação de insegurança alimentar e nutricionais e aqueles atendidos pela rede socioassistencial.

Os preços dos produtos, adquiridos pela $\mathrm{CONAB}$, são definidos em relação à média dos preços praticados nos mercados regionais e o limite de aquisições é definido por decreto, estabelecendo-se anualmente um valor máximo por família. Com isso, são seis modalidades operacionais do programa: i) compra direta da agricultura familiar; ii) formação de estoques pela agricultura familiar; iii) compra com doação simultânea; iv) PAA-Leite, v) compra institucional e vi) aquisição de sementes.

Os alimentos adquiridos diretamente dos agricultores familiares ou de suas associações e cooperativas são destinados à formação de estoques governamentais ou à doação para as pessoas em situação de insegurança alimentar e nutricionais, atendidas pelas 
redes socioassistenciais e pelos equipamentos públicos de alimentação e nutrição. No ano de 2008, surgiu um novo reforço na constituição de mercados institucionais para a segurança alimentar, no qual a modalidade de aquisição de alimentos para atendimento da alimentação escolar foi incorporada ao PAA por meio da Resolução do Grupo Gestor do PAA (GGPAA), em agosto de 2008 .

Em relação a essa modalidade, ressaltamos a possibilidade de promover a produção de agricultores familiares e a demanda das escolas para atendimento da alimentação escolar. $\mathrm{O}$ GGPAA ainda prevê que o Fundo Nacional para o Desenvolvimento da Educação (FNDE) definirá a sistemática e os procedimentos operacionais em relação aos produtos adquiridos, estabelecendo uma porcentagem mínima de $30 \%$ do valor a ser gasto com alimentação escolar para a aquisição de produtos da agricultura familiar local. Além de novos recursos para a comercialização institucional de seus produtos, outra vantagem para os agricultores familiares, com esta nova conquista, é a de que a demanda por alimentação escolar seja constante, diferentemente do que ocorre no PAA, pois apresenta descontinuidades por causa do fluxo de recursos e articulações políticas (SILVA, 2013).

Além do mais, ocorreu outra mudança no programa com a Lei ${ }^{\circ} 12.512 / 2011$, regulamentada pelo Decreto $\mathrm{n}^{\circ}$ 7.775/2012, a qual promove a parceria com estados, municípios e consórcios públicos. Assim, abriu-se a possibilidade da execução do PAA, mediante a celebração de Termo de Adesão, e dessa forma proporciona a ampliação do programa, tem menos burocracia, além de possibilitar a realização do pagamento pela União diretamente ao agricultor familiar, que o recebe por meio de um cartão bancário específico para o recebimento dos recursos do PAA. (BRASIL, 2012).

Assim, os beneficiários fornecedores podem participar do programa individualmente (desde que apresentem a Declaração de Aptidão ao PRONAF-DAP), por meio de suas cooperativas ou, inclusive, por outras organizações formalmente constituídas como pessoa jurídica de direito privado, contanto que apresente o DAP, Especial Pessoa Jurídica ou outros documentos definidos pelo GGPAA. Em seguida, é realizada a solicitação de senha para acessar ao Sistema de Informação do PAA (SISPAA), assinatura de Termo Adesão, pactuação de valores e metas entre os entes (estados, municípios e consórcios públicos) e o Ministério do Desenvolvimento Social (MDS), publicação de portaria ministerial propondo valores e metas físicas, aceite por parte dos entes do Plano Operacional, pactuação local, cadastramento da Proposta no SISPAA, aquisição e distribuição de alimentos, pagamento de Fornecedores e Apoio Financeiro aos Executores. 
Com a criação do PAA, o tema dos mercados institucionais passa a ganhar destaque nas discussões na abordagem do programa, pois trata-se de um setor que envolve as três esferas governamentais (federal, estadual e municipal) para operações de compras de alimentos, com vistas a atender escolas, universidades, hospitais, entre várias instituições públicas que necessitem de alimentação. Grisa e Porto (2015) consideram que, em termos conceituais, os mercados institucionais não são necessariamente algo novo, pois todos os mercados são permeados por instituições. Contudo, no contexto das políticas públicas, o mercado institucional refere-se ao papel do Estado na construção/mediação de mercados na realização de compras governamentais a fim de atender o programa e, diante disso, as autoras delimitam a configuração de mercado institucional:

Neste contexto, mercado institucional refere-se a uma configuração específica de mercado em que as redes de troca assumem uma estrutura particular, previamente determinada por normas e convenções negociadas por um conjunto de atores e organizações, onde o Estado assume um papel central, notadamente por meio de compras públicas (GRISA; PORTO, 2015, p. 158).

O mercado é circunscrito por instituições, nas quais são estabelecidas regras de como cooperar ou competir, mas neste contexto, o mercado institucional é um mercado criado pelo Estado para atender a agricultura familiar através da política pública. A partir disso, a inserção dos agricultores nos mercados é um dos fatores que contribuem para o desenvolvimento rural que, por sua vez, resulta na inserção no sistema capitalista de produção, a partir da lógica do mercado. Com o PAA, os alimentos são produzidos no local e consumidos preferencialmente no mesmo local da produção, na perspectiva de reduzir a distância entre produção e consumo, permitindo estimular a economia local.

Silva e Silva (2011) defendem que a possibilidade desses novos mercados abriu caminho para novos empreendimentos associativos, uma vez que o programa garante a comercialização de parte da produção. Além disso, para ter acesso a esse mercado, cria-se a necessidade de reestruturação interna dos empreendimentos rurais, diante das exigências comerciais como: regularização tributária, sanitária e jurídica.

Não podemos somente entrar no mérito da construção ou concepção do programa, é importante destacar também a evolução do PAA no Brasil, a partir dos seus avanços e limitações dessa política no país. Em termos operacionais, os recursos aplicados no PAA foram crescentes desde sua implantação em 2003 até 2012, entretanto verifica-se decréscimo das ações do programa nos anos posteriores, o qual de acordo com os relatórios anuais da 
CONAB (2015). Essa redução é devida as características de cada região, a exemplo da seca ocorrida no Nordeste, redução da demanda de Compra Direta e cancelamento da modalidade Formação de Estoque.

A região Sul, desde a implantação do PAA até o ano de 2012, foi a região que mais concentrou recursos para execução do programa no Brasil, porém tem apresentado redução exponencial. Situação semelhante à da região Nordeste, esta foi a segunda região que obteve maior número de repasses financeiros do PAA desde 2003 até 2012, com decréscimo em 2011 e recuperação em 2014, ao passo que as regiões Centro-Oeste e Norte registraram menor participação no PAA.

De acordo com Hentz e Hespanhol (2019), no ano de 2013 o decréscimo foi de $61 \%$ dos recursos investidos do PAA no cenário nacional, a recuperação é retomada em 2014, e novamente decresce em 2015. As regiões Nordeste e Sul, desde 2003 até 2015, apresentaram maior parcela na alocação dos recursos do PAA, tal fato pode ser explicado pelo maior grau de organização coletiva e de produção de pequenos agricultores, além da elevada concentração de estabelecimentos da agricultura familiar respectivamente nas regiões Nordeste e Sul, em contrapartida as regiões Centro-Oeste e Norte correspondem às regiões com menor número de estabelecimentos familiares, como demonstrado no Cartograma 1 abaixo:

\section{Cartograma 1}

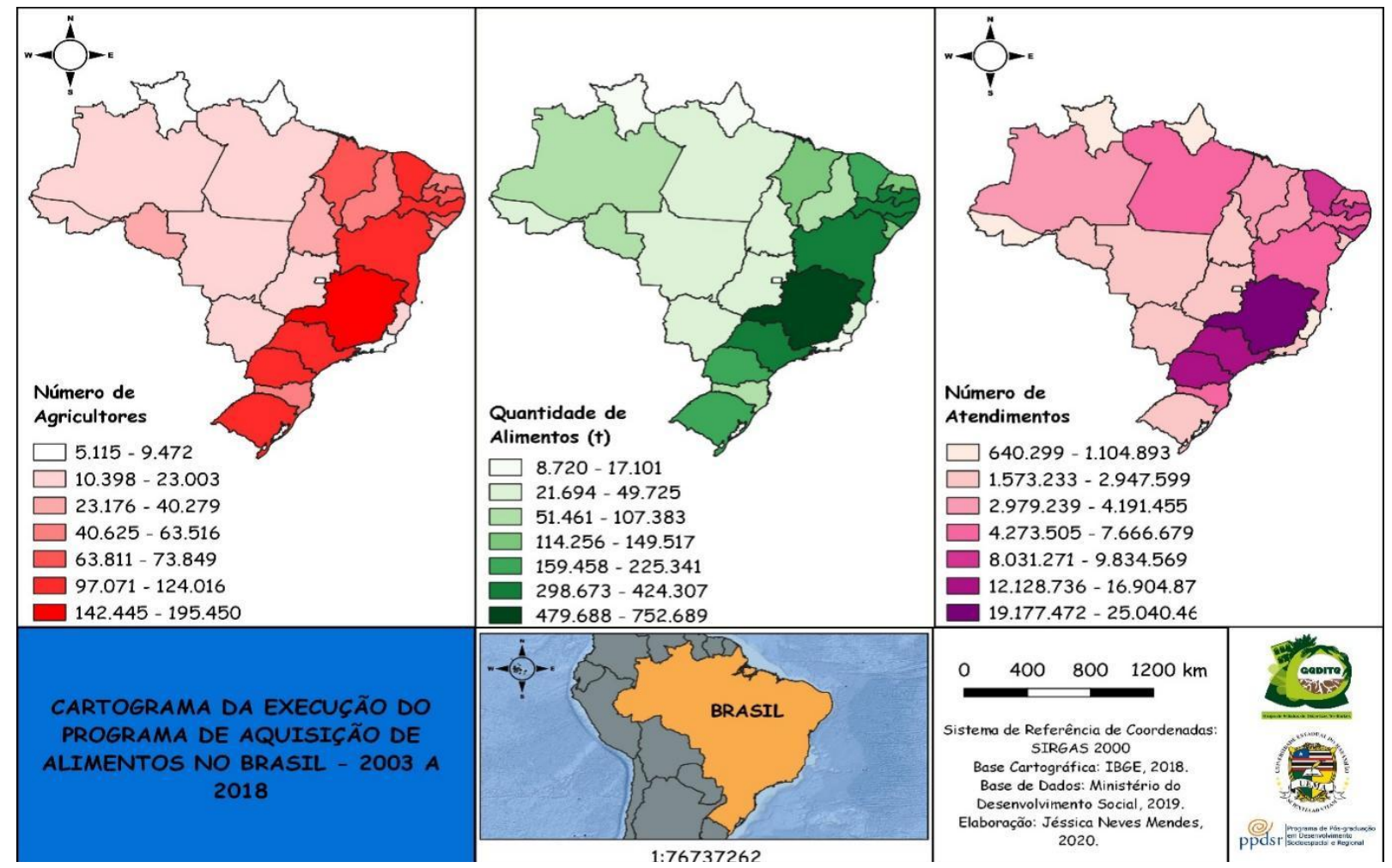

Elaboração: Os autores. 
Tendo em vista que o programa requer uma organização social, determinadas regiões rurais ou segmentos de agricultores familiares reúnem condições mais favoráveis para acessar os recursos em detrimento de outras, além de outras questões como a dificuldade de logística; baixos preços pagos para alguns produtos; burocratização de acesso ao programa; carência de documentação por parte dos agricultores; desconfiança em relação ao poder público; falta de articulação entre produtores e gestores do programa. Estes são alguns dos fatores que implicam nas limitações de acesso ao PAA.

Bacelar e Favareto (2020) analisam que de fato o impacto das políticas públicas voltadas para agricultura familiar existiu, mas não foi o suficiente para fazer frente às velhas ruralidades. Assim, o que se incorporou foi uma preocupação ambiental traduzida nos programas e com experiências agroecológicas. Ademais, nos governos petistas, na perspectiva de incorporar as demandas dos movimentos sociais, atendeu um conjunto de reinvindicações, como a ampliação do PRONAF e de vários programas complementares, a exemplo do PAA, e outras iniciativas não diretamente ligadas à agricultura, por meio de melhorias na infraestrutura dos assentamentos rurais.

Após um conjunto de inovações de políticas voltadas para a agricultura familiar e após a crise política e fiscal em 2015, o cenário muda completamente, sendo sumariamente resumido a cortes e descontinuidades nas políticas até aqui elencadas, além de reorganização de velhas estruturas que não permitem mudanças estruturais no campo. Ainda assim, apesar das limitações dos próprios programas, um dos principais determinantes para essa desestruturação foi a ruptura do MDA e MDS, órgãos estes que garantiam a institucionalidade das políticas de agricultura familiar.

Segundo Alentejano (2020), outro fator a ser somado nesses acontecimentos trata-se do avanço do agronegócio, priorizado do governo FHC, perpassando também nos governos Lula e Dilma e com forte continuidade no governo Bolsonaro, resultando no abandono da reforma agrária e demarcação de terras indígenas e quilombolas. Assim, o diálogo construído com os movimentos sociais é destroçado juntamente com as políticas, dando lugar ao autoritarismo, a repressão e o caminho livre de atuação para o capital estrangeiro, reforçando os laços e braços firmados do Estado para com o capital (SOUSA, 2020). Nesse sentido, o Instituto Nacional de Colonização e Reforma Agrária (INCRA) passa a ser subordinado ao Ministério da Agricultura, bem como as políticas da agricultura familiar, sobrevivendo em um Ministério que possui um histórico de dar suporte a produção de grande escala. Fernandes et al (2020) aponta que em 2019 a reforma agrária sofreu a maior retração da história desde 
1985 (quando foram criados apenas três assentamento), uma vez que nesse ano nenhum assentamento foi criado.

Outro agravante inicia-se no primeiro trimestre de 2020, com a declaração da Organização Mundial da Saúde (OMS) sobre a pandemia da Covid-19, doença causada pela nova Severe Acute Respiratory Syndrome Coronavirus 2 (SARS-CoV-2). Esta trouxe uma pandemia com implicações para a economia mundial, instaurando uma crise na saúde global, com efeitos sob a confiança do consumidor, dos mercados financeiros, do setor de turismo e na quebra nas cadeias de valor e produção, deprimindo as expectativas de crescimento em escala mundial. A pandemia da Covid-19 emerge à luz dos problemas sociais agravados nos últimos anos demonstrando, de forma enfática, as várias fragilidades do país, o que também permitiu o retorno de pautas que antes foram esquecidas com as mudanças de governo, como a problemática da fome no Brasil e a segurança alimentar, em que o papel da agricultura familiar demonstrou-se de grande importância por meio dos circuitos curtos de comercialização e dos mercados institucionais para o abastecimento da população em meio à crise sanitária da Covid-19, haja vista Medida Provisória ${ }^{\circ}$ 957, de abril de 2020, destinando R\$ 500 milhões para a segurança alimentar e nutricional por meio do PAA para o enfrentamento da emergência de saúde decorrente do coronavírus.

Dessa forma, políticas como PAA são importantes para o incentivo à produção local, entretanto os próprios arranjos institucionais regulamentados pelo Estado, que criam formas de ingressar o pequeno produtor no mercado, desarticulam a política frente ao capital, colocando o PAA diante de incertezas perante a conjuntura socioeconômica do país, haja vista as descontinuidades políticas como o próprio PFZ, sendo grande estratégia intersetorial de segurança alimentar, embora se mantiveram o PAA e o PNAE. Tal importância pode ser elencada no estado do Maranhão, o qual, segundo Ministério do Desenvolvimento Social (2018) entre 2003 a 2018, recebeu R \$ 286.952.907,58 em recursos do MDS com total de 70.273 agricultores atendidos com o PAA, sendo executado em dois tipos de modalidade: a Compra Direta e a Doação Simultânea, ambos executados pelo estado e pelos municípios por meio da adesão municipal e adesão estadual.

Na Adesão Municipal, o município formaliza o termo de adesão e coordena os recursos diretamente do Ministério da Cidadania para os agricultores, neste caso, o PAA é coordenado pelo próprio município, ao passo que na Adesão Estadual ocorre de forma semelhante, mas com algumas ressalvas, visto que o coordenador do programa é o governo estadual, o qual também coordena os recursos do Ministério da Cidadania. Destarte, com base 
dos dados da CONAB, entre 2009 a 2019 o PAA-CONAB contemplou 106 municípios do Maranhão com 16.143 beneficiários fornecedores e 4.107 entidades recebedoras, enquanto o PAA Termo de Adesão atendeu 18.501 agricultores, 3.948 entidades e 1.640 .394 de pessoas (CONAB, 2020).

Dada a complexidade do programa, nota-se que o programa ainda não alcança a cobertura total dos municípios do estado, assim como os agricultores familiares. Ao passo que também é válido ressaltar que, para o acesso de tais políticas para a agricultura familiar, é necessário considerar o fator organização, ou seja, quanto mais estruturada e articulada as organizações dos agricultores, maior é a possibilidade de novas adesões, com isto destacam-se os municípios que obtiveram maior quantitativo de beneficiários fornecedores, como exemplo Zé Doca, Itapecuru Mirim, Imperatriz e São Luís. Assim, apesar dos avanços por meio da implantação de políticas públicas voltadas para agricultura familiar, este setor tem assumido função econômica para produção de alimentos alternativos e para a segurança alimentar através de políticas voltadas para o combate à fome, assim, estabelece formas de resistências e existências, tal exemplo pode ser enfatizado no assentamento Galvão Cantanhede.

\section{A Dinâmica do Assentamento e o Mercado Institucional}

O município de Cantanhede, bem como o estado do Maranhão, caracteriza-se pela presença da agricultura familiar, sendo 87\% (1197) dos estabelecimentos agropecuários no município são predominantemente da agricultura familiar. Não obstante, a produção agropecuária em Cantanhede também é marcada produção familiar, sobretudo, com a produção de arroz, feijão, mandioca e milho.

Dessa forma, de acordo com a CONAB (2020), o primeiro ano de adesão do município no PAA-CONAB foi a partir de 2011 e com término em 2012, registrando o maior número de acesso nesse período com 89 produtores participantes. Enquanto isso, na modalidade termo de adesão, o primeiro ano de acesso foi a partir de 2013 com 36 produtores também registrando o maior número de acesso até o ano de 2020, vejamos o Gráfico 1 abaixo: 


\section{Gráfico 1}

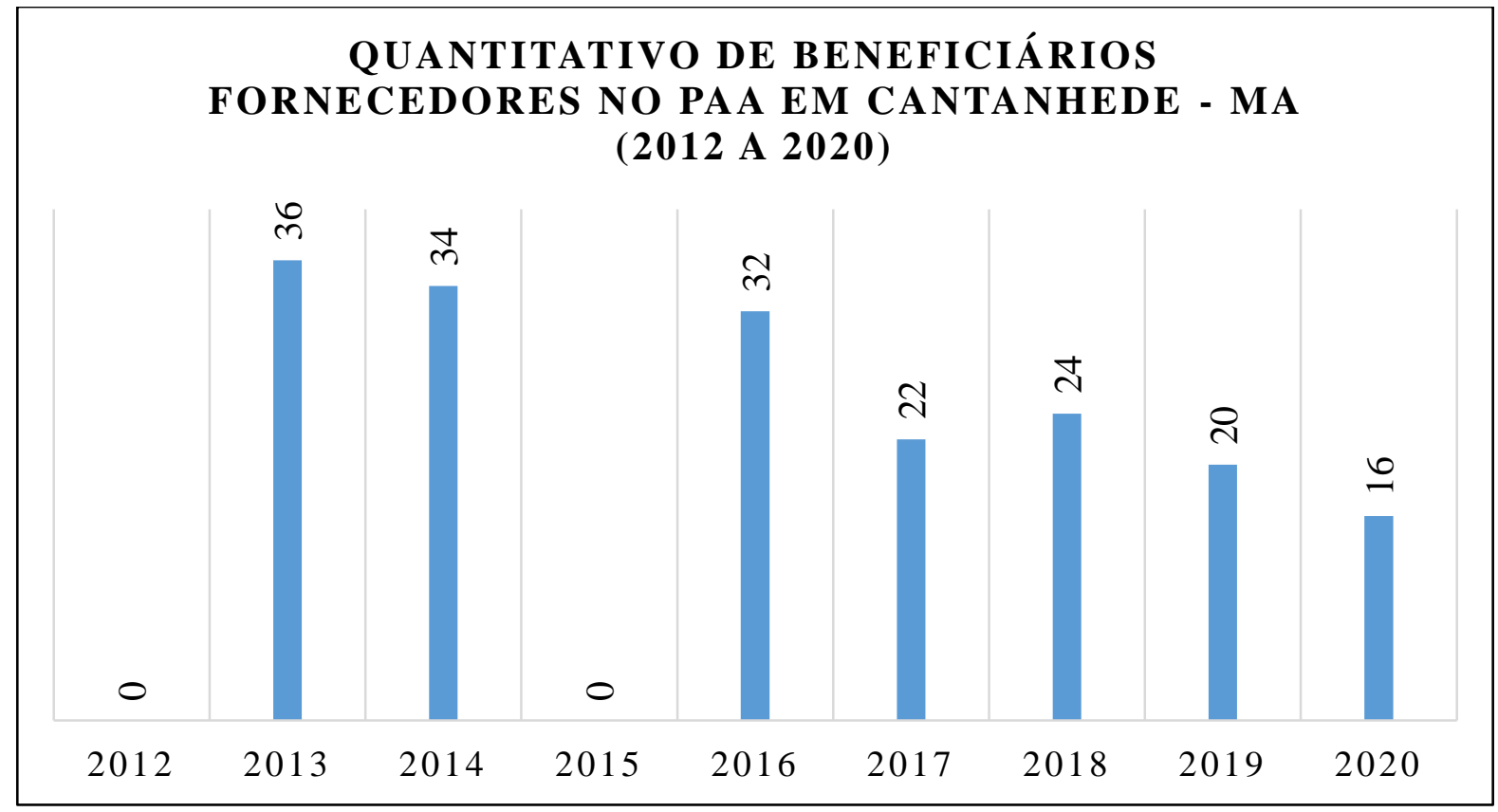

Fonte: Ministério da Cidadania, 2020.

Org.: Os autores.

Dentre os assentamentos que estavam recebendo o PAA no município de Cantanhede, estão o Galvão Cantanhede e São Leopoldo. As associações envolvidas com o PAA são as das Quebradeiras de Coco e dos Agricultores Familiares. Assim, conforme os 15 beneficiários entrevistados que participaram da aplicação dos questionários, os quais estavam diretamente ligados ao PAA pelo assentamento Galvão Cantanhede -, todos estes possuíam como atividade principal a agricultura, sendo ligados às cooperativas e/ou associações.

Entretanto, é importante atentarmos para o baixo número de beneficiários fornecedores do PAA no município, evidenciando a baixa capilaridade do programa, bem como o contínuo recuo de recursos para a execução do programa, colocando em questão a continuidade do programa. Apesar do aumento de recursos e beneficiários do PAA, cuja maior expressividade se deu em 2012, o programa esteve longe de beneficiar a totalidade dos agricultores familiares no país, pois, como abordam Saron, Neves Neto e Hespanhol (2017), além do número reduzido de agricultores familiares contemplados pelo PAA, outro problema ocorreu na execução do programa: o perfil do agricultor familiar beneficiado que, apesar de ser definido em 2003 como público prioritário no universo da agricultura familiar os segmentos mais pobres, ainda ocorre o inverso, os segmentos mais capitalizados permanecem com a maior parte dos recursos do PAA.

Em relação ao acesso para o assentamento, este é realizado pela travessia do rio Itapecuru por meio de uma pequena balsa (Figura 1). De acordo com o então secretário de 
agricultura Sebastião Brandão, a prefeitura de Cantanhede estava com um projeto de construção de uma ponte para facilitar a locomoção dos moradores do assentamento Galvão Cantanhede. A travessia do rio por meio da balsa (Figura 2) é realizada por dois funcionários da prefeitura, sendo o horário limite para término do funcionamento da balsa às 23 horas.

Figura 1 - Assentamento Galvão Cantanhede.

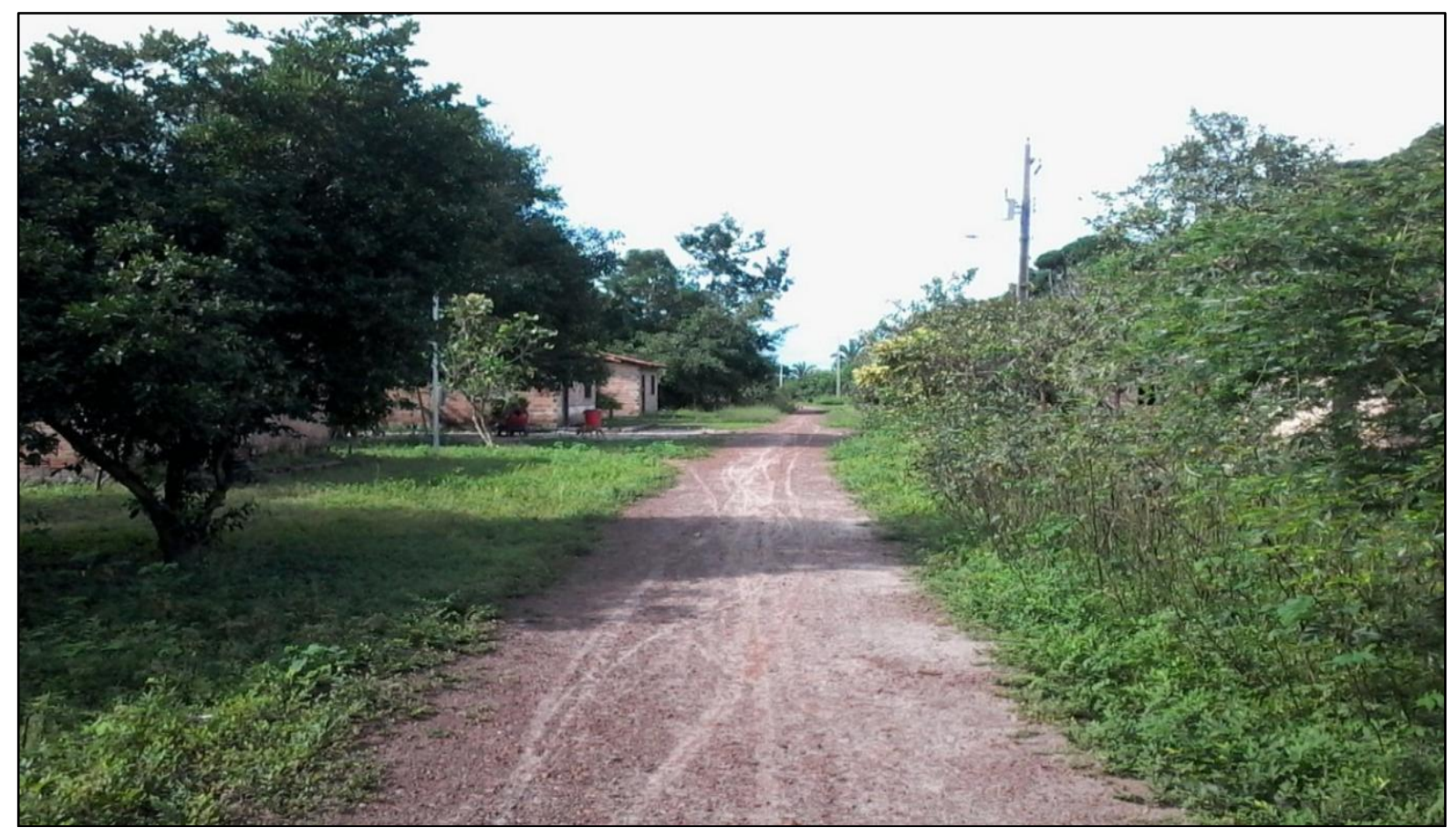

Fonte: MENDES, 2018.

Figura 2 - Travessia do rio Itapecuru para ida ao assentamento Galvão Cantanhede.

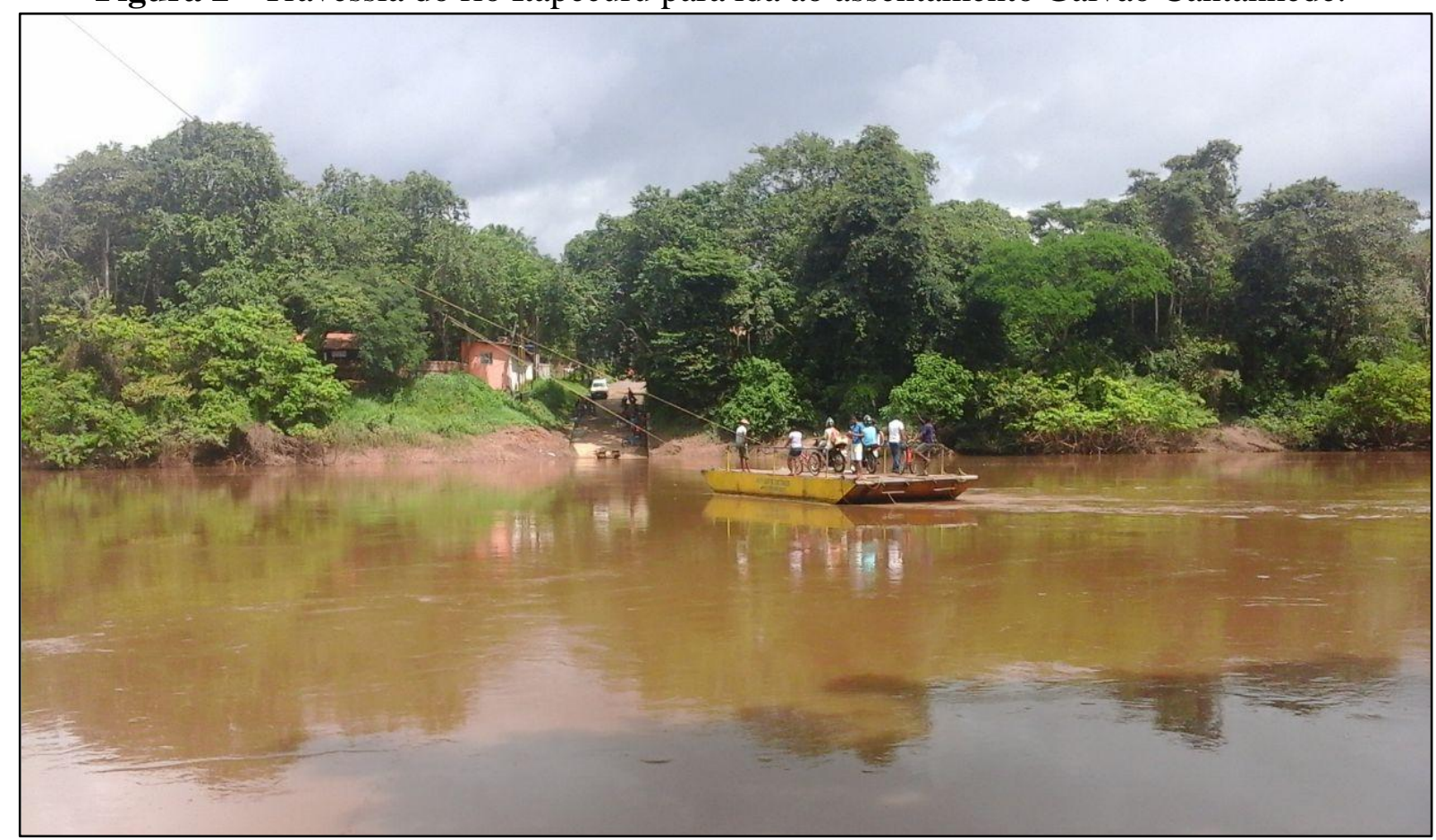

Fonte: MENDES, 2018. 
Ainda nessa perspectiva, o Gráfico 2 demonstra que, no município, a modalidade do PAA mais acessada pelos agricultores do assentamento é: a doação simultânea a mais acessada com 50\%, que consiste no incentivo para a produção local da agricultura familiar com a finalidade de atender as necessidades alimentares das entidades participantes. A segunda mais acessada é a compra local com 33\%, seguida pela compra direta com $17 \%$.

\section{Gráfico 2}

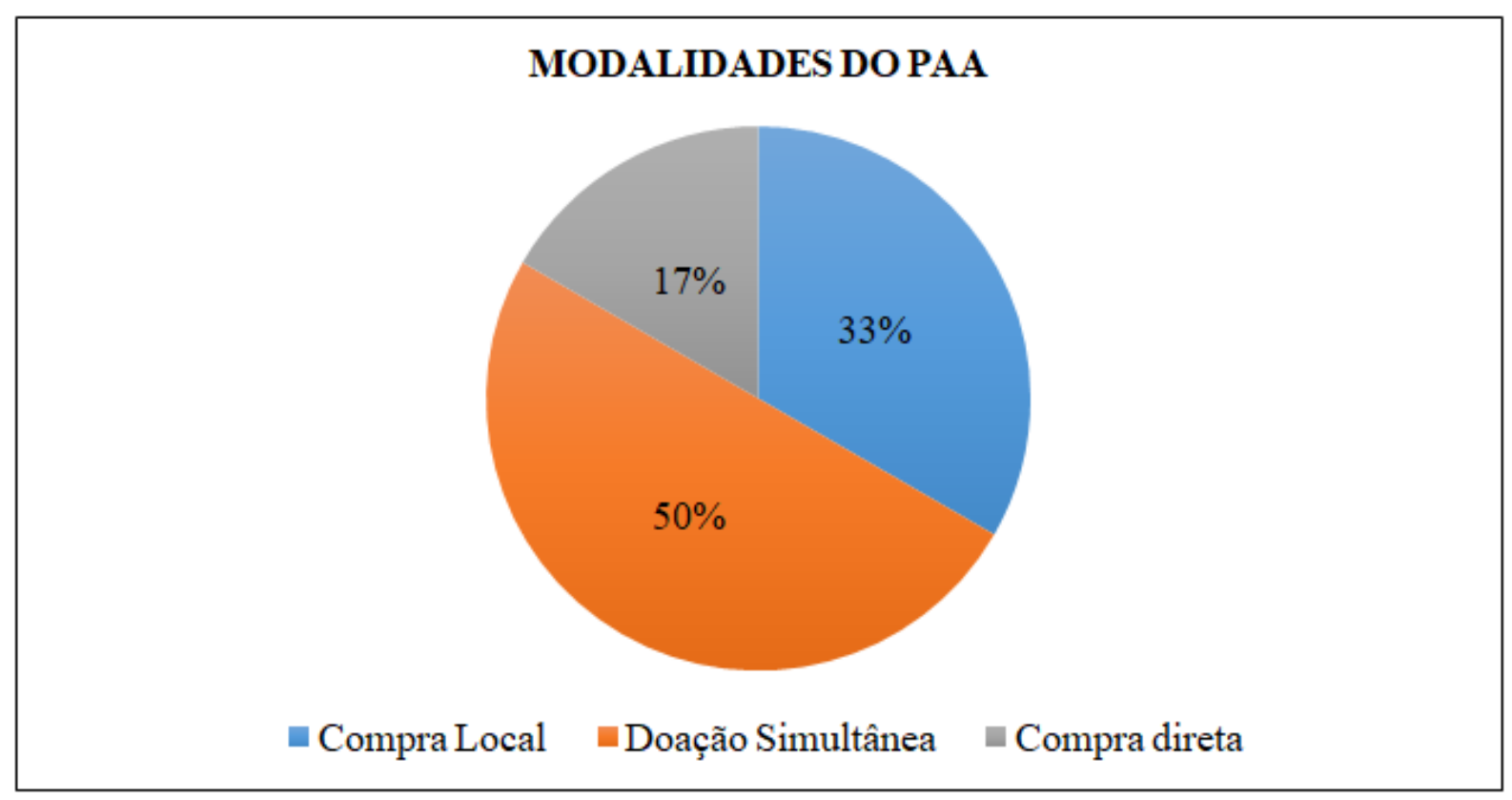

Org.: MENDES, 2018.

Os principais produtos cultivados pelos agricultores do assentamento Galvão Cantanhede são: mandioca, milho, arroz, feijão, alface, vinagreira, melancia, abóbora, maxixe, melão, banana, mamão, quiabo, coco babaçu, farinha de mandioca, pepino, bolo caseiro, batata doce, limão, laranja, couve, cebolinha, poupa de frutas, pimenta, além da venda de carne bovina, suína, frango e peixe. Assim, o principal destino dos produtos são as escolas municipais (Gráfico 3), como apontaram os assentados. 
Gráfico 3

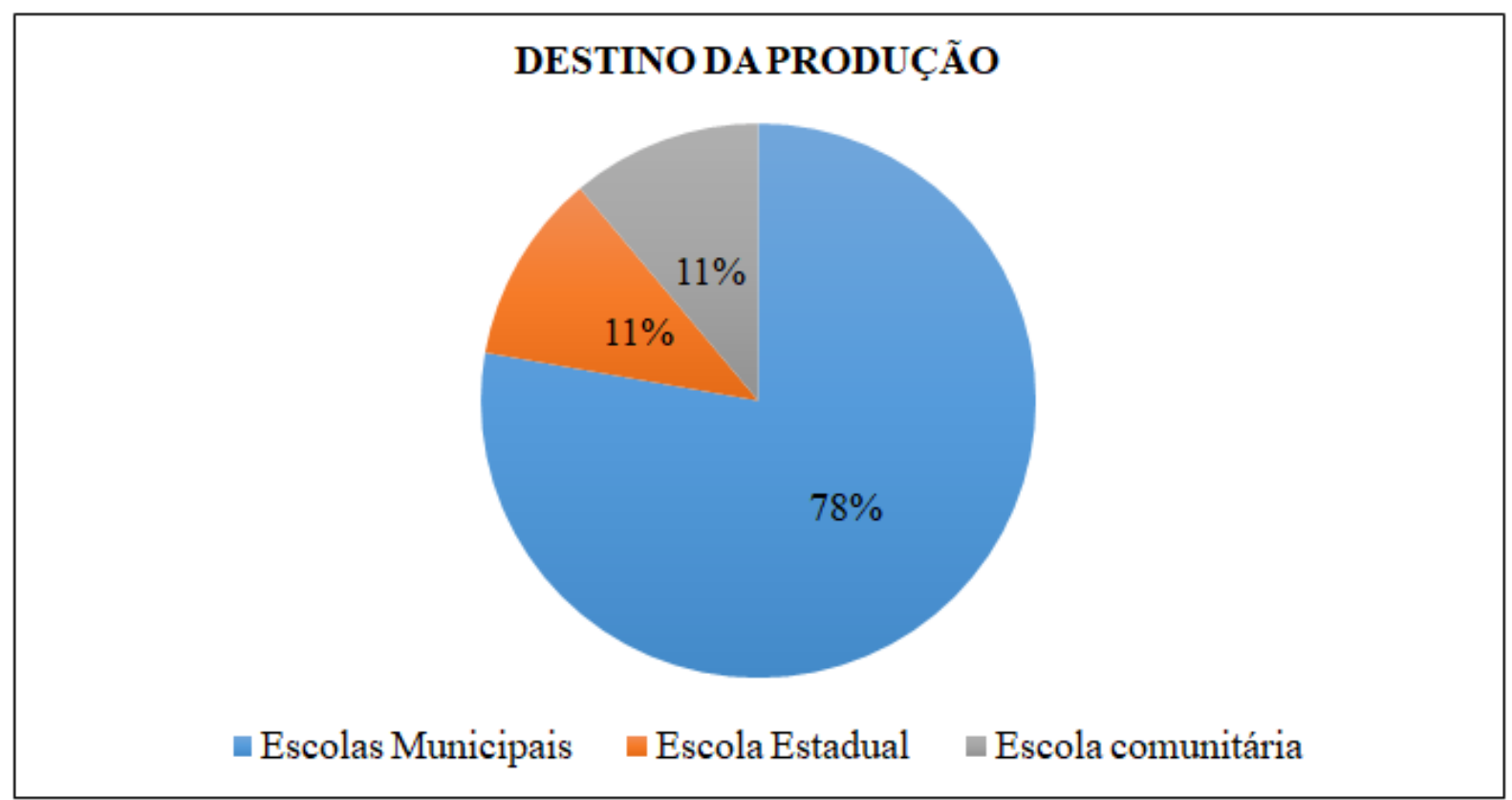

Org.: MENDES, 2018.

Além disso, na entrevista com o secretário de agricultura de Cantanhede Sebastião Brandão, este apontou um dos principais problemas de infraestrutura nos assentamentos para o escoamento dos produtos do PAA, trata-se do transporte, ainda que antigamente a estrada para o acesso do assentamento fosse muito precária, houve apenas uma pequena melhoria dessa e esse fator ainda se mantém como um dos principais entraves.

Conforme Grisa e Porto (2015), embora o programa tenha intersetorialidade no âmbito nacional, ainda permanece um desafio político e institucional, no qual nem sempre o poder público municipal/estadual é parceiro na execução do programa, pois, não raro, as organizações da agricultura familiar não estão constituídas ou encontram-se em uma fase inicial de estruturação; ou as entidades socioassistenciais também apresentam limitações de recursos humanos e estruturais; e nem sempre há organizações sociais mediadoras que tomam a iniciativa ou potencializam a articulação política e a governança necessária para a execução do PAA.

Segundo os entrevistados, os principais entraves para a adesão do PAA no assentamento são a falta de apoio à produção, falta de adubos e mercado. Por vezes as famílias não tinham o produto adequado, além de conviverem com atraso no pagamento, falta de mercado, seca e desmatamento. Entretanto, no questionário com os assentados, 38\% apontaram que não houve problemas com o acesso do PAA. Além do mais, 7\% apontaram que há problemas como acesso ao banco e a falta de informação, conforme Gráfico 4 abaixo: 
Gráfico 4

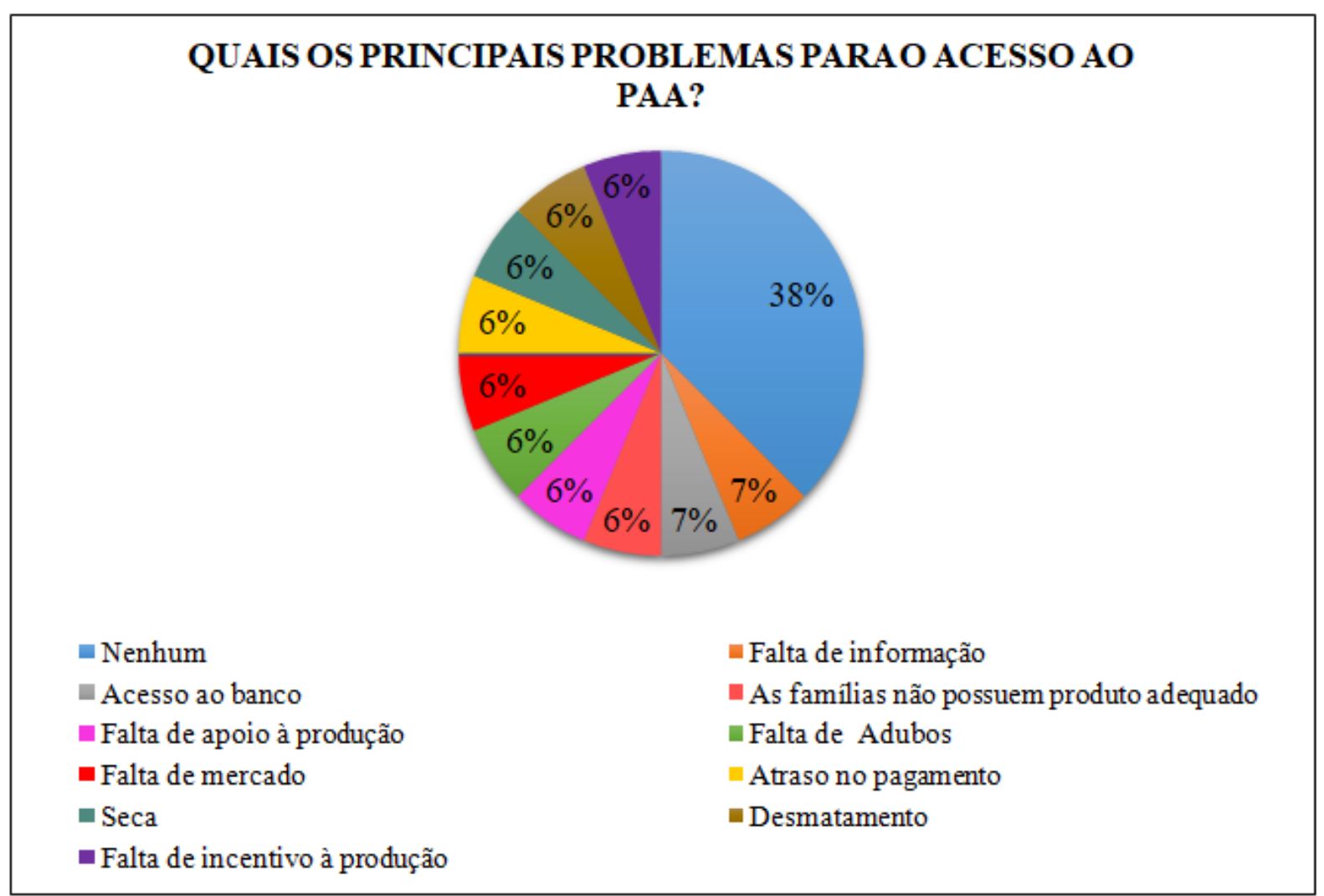

Org.: MENDES, 2018.

É válido ressaltar também que para o acesso de tais políticas que visam agricultura familiar, é necessário considerar o fator organização, quanto mais estruturada e articulada às organizações dos agricultores, maior é a possibilidade de novas adesões, com isto, destacamse os municípios que obtiveram maior quantitativo de beneficiários fornecedores. A oferta de alimentos é outro fator a ser ponderado pois parte das demandas de compras de alimentos nos pontos de comercialização e dos serviços básicos que demandam por alimentação, como: saúde, educação, restaurantes populares, segurança pública e instituições socioassistenciais.

No questionamento sobre a opinião dos assentados do Galvão Cantanhede em relação ao PAA, a maior parte apontou que o programa foi bom, principalmente, no que se refere à melhoria na renda dos agricultores após o acesso. Dessa forma, no questionamento sobre a melhoria da renda dos assentados após o PAA, a maioria dos beneficiários apontou que houve melhoria em relação à renda familiar. Além disso, os assentados mencionaram que, com o programa, houve aumento em relação ao quantitativo e a variedade dos produtos, tanto na propriedade, quanto na comercialização.

Em contrapartida, os entraves para adesão do programa persistem, uma vez que a maioria dos assentados que respondeu os questionários apontaram que não possuem 
conhecimento do programa, evidenciando a falta de informação e divulgação do PAA. Além disso, os agricultores relataram que há certa exigência quanto à entrega dos produtos, pois é exigida certificação dos alimentos e, ainda assim, há receio por parte dos agricultores na falta de continuidade do programa, pois durante a execução das entrevistas, alguns destes questionaram sobre o atraso no pagamento para a execução do programa.

\section{Considerações Finais}

O enfoque territorial presente nas atuais políticas de planejamento, ainda incipiente, proporciona a definição de estratégias para o desenvolvimento, tais como a criação do PRONAF e dos Mercados Institucionais, onde podemos inferir como políticas de compensação frente a grande concentração de terras e de renda estabelecidas historicamente no país. O PAA constituiu-se como uma das estratégias que contribuíram para a saída do Mapa da Fome da ONU, por meio do PFZ. Entretanto, em meio as crises políticas e orçamentárias, o PAA não se constitui como um direito à alimentação como recomenda a Constituição Brasileira. Assim, o PAA por ter caráter de programa pode ser reestruturado ou até mesmo interrompido, o que reforça a necessidade de transformação do programa em uma política de Estado, a exemplo do PNAE.

Além disso, a relevância do PAA está no fato de não ser necessariamente um programa agrícola, alimentar e social, mas que fomenta discussões no âmbito do desenvolvimento territorial por meio do fortalecimento das atividades produtivas locais ao oferecer mecanismos para a produção e comercialização das atividades rurais. O PAA, de fato, trouxe avanços no fortalecimento da agricultura familiar no assentamento como apontado nos questionários, com melhorias na renda, assim como, na produção dos alimentos para o consumo tanto dos beneficiários quanto dos fornecedores.

Assim, programas como esse são de grande importância, pois permitem a aproximação entre a sociedade e os gestores públicos, uma vez que valorizam o papel que a agricultura familiar exerce no desenvolvimento socioeconômico do país, incorporando estes setores na economia. Reforça-se a ideia de que programas com grandes amplitudes, como o PAA, requerem organização de ambas as partes, poder público e sociedade civil, para que a política seja executada com mais eficiência possível afastando assim, possíveis reduções orçamentárias em razão da desorganização da sua estrutura. 
Diante disso, houve um considerável envolvimento por parte da secretaria de agricultura do município de Cantanhede - para o acesso ao programa. Entretanto, o número de agricultores contemplados pelo PAA no assentamento Galvão Cantanhede é considerado baixo, tendo em vista que para um programa do porte do PAA, tal qual demanda uma grande quantidade de recursos, somente dezesseis famílias assentadas, das 295 existentes, acessamno. Desse modo, os entraves para adesão do programa persistem, uma vez que os assentados enfatizaram que não possuem conhecimento do programa, evidenciando a falta de informação e divulgação do PAA.

De forma contrastante, é notório o discurso da valorização da agricultura familiar no programa, tendo em vista a produção local e consumo dos produtos cultivados, na perspectiva de integrá-los na economia do Estado, passando a ser novos elementos nos mercados institucionais apoiados e estruturados pelo Estado. Em contrapartida, o PAA retrocede diante do desmonte sinalizado ano após ano, colocando em xeque aproximados vinte anos de estruturas de apoio à agricultura familiar, culminando na redução nos repasses de recursos financeiros e desarticulando as atividades produtivas.

\section{Referências}

ALENTEJANO, Paulo Roberto Raposo. As políticas do governo Bolsonaro para o campo: a contrarreforma agrária em marcha acelerada. Revista da Anpege, [s. l], v. 16, n. 29, p. 351390, 2020. Disponível em: https://ojs.ufgd.edu.br/index.php/anpege. Acesso em: 23 jan. 2021.

BACELAR, Tania; FAVARETO, Arilson. O papel da agricultura familiar para um novo desenvolvimento regional no Nordeste: uma homenagem a celso furtado. Revista Econômica do Nordeste, Fortaleza, v. 51, p. 9-29, ago. 2020.

BRASIL. Decreto n. 8.865, de 29 de setembro de 2016. Transfere a Secretaria Especial de Agricultura Familiar e do Desenvolvimento Agrário para a Casa Civil da Presidência da República e dispõe sobre a vinculação do Instituto Nacional de Colonização e Reforma Agrária - INCRA. Disponível em: http://www.planalto.gov.br/ccivil_03/_Ato20152018/2016/Decreto/D8865.htm. Acesso em: 23 jan. 2021.

Decreto $\mathrm{n}^{\circ}$ 7.775/2012, de 4 de julho de 2012. Regulamenta o art. 19 da Lei $\mathrm{n}^{\circ}$ 10.696, de 2 de julho de 2003, que institui o Programa de Aquisição de Alimentos, e o Capítulo III da Lei $\mathrm{n}^{\circ} 12.512$, de 14 de outubro de 2011, e dá outras providências. Disponível em: http://www.planalto.gov.br/ccivil_03/_ato2011-2014/2012/decreto/d7775.htm Acesso em: 23 jan. 2021. 
Lei $\mathrm{n}^{\text {o }} 11.947$ de 16 de junho de 2009. Disponível em: <http://www.planalto.gov.br/ccivil_03/_Ato2007-2010/2009/Lei/L11947.htm>. Acesso em: 25 maio 2019.

Cartilha Programa de Aquisição de Alimentos. Disponível em: <http://www.mda.gov.br/sitemda/sites/sitemda/files/user_arquivos_64/CARTILHA_PAA_FI NAL.pdf> Acesso em: 29 dez 2015.

CONAB. O Fortalecimento da Agricultura Familiar: programa Fome Zero. Disponível em: <http://www.conab.gov.br/conteudos.php?a=1125> Acesso em: 29 dez 2015.

. Programa de Aquisição de Alimentos: legislação Básica / Companhia Nacional de Abastecimento. Brasília: Conab, 2018. 271 p.

. Dados referentes ao Programa de Aquisição de Alimentos no Brasil. Brasília: Conab, 2020. [Informações obtidas através do Sistema Eletrônico do Serviço de Informação ao Cidadão (e-sic)].

FERNANDES, Bernardo Mançano. MOVIMENTOS SOCIOTERRITORIAIS E MOVIMENTOS SOCIOESPACIAIS: contribuição teórica para uma leitura geográfica dos movimentos sociais. Revista Nera, Presidente Prudente, n. 6, p. 14-34, 2005. Semestral.

GRISA, Catia. PORTO, Silvio Isopo. Dez anos de PAA: As contribuições e os desafios para o desenvolvimento rural. In: Políticas públicas de desenvolvimento rural no Brasil / Organizadores Catia Grisa [e] Sergio Schneider. - Porto Alegre: Editora da UFRGS, 2015.

HAESBAERT, Rogério; LIMONAD, Ester. O território em tempos de globalização. Etc, Espaço Tempo e Crítica: Revista Eletrônica de Ciências Sociais Aplicadas, [s. l], v. 1, n. 2, p. 39-52, 15 ago. 2007.

HENTZ, Carla.; HESPANHOL, Rosangela Aparecida de Medeiros. O Programa de Aquisição de Alimentos - PAA: a evolução de uma política pública múltipla. Revista Geosul, Florianópolis, v. 34, n. 72, p. 415-434, mai./jago. 2019. Disponível em: https://periodicos.ufsc.br/index.php/geosul/article/view/1982-5153.2019v34n72p415. Acesso em: 23 jan. 2021.

HESPANHOL, Rosangela Aparecida de Medeiros. Programa de Aquisição de Alimentos: limites e potencialidades de políticas de segurança alimentar para a agricultura familiar. Sociedade \& Natureza, Uberlândia, v. 25, p. 469-483, 2013.

IBGE. Censo Demográfico 2010. Disponível em: <https://censo2010.ibge.gov.br/resultados.html>. Acesso em: 23 jan. 2021.

MARX, Karl, 1818 - 1883. Contribuição à crítica da economia política. 3. ed. São Paulo: Martins Fontes, 2003.

1818 - 1883. A ideologia alemã. Tradução: Luís Claudio de Castro e Costa. São Paulo: Martins Fontes, 1998. 
MDA. Plano Territorial de Desenvolvimento Rural Sustentável: guia para o planejamento (Documento de apoio $\mathrm{n}^{\circ}$ 02). Brasília: MDA/SDT, 2005.

MEDEIROS, Rosa Maria Vieira (comp.). Território, espaço de identidade. In: SAQUET, Marcos Aurélio; SPOSITO, Eliseu Savério (org.). Territórios e territorialidades: teorias, processos e conflitos. São Paulo: Expressão Popular, 2008. p. 217.

MENDES, Jéssica Neves. Caracterização do acesso ao Programa de Aquisição de Alimentos no assentamento Galvão Cantanhede, no município de Cantanhede - MA, a partir do Plano Territorial de Desenvolvimento Rural Sustentável. Cantanhede, 2018. 74 f. Monografia (Graduação) - Curso de Geografia Licenciatura, Universidade Estadual do Maranhão, 2018.

MINISTÉRIO DO DESENVOLVIMENTO SOCIAL. Dados referentes ao Programa de Aquisição de Alimentos no Brasil. Brasília: MDS, 2018. [Informações obtidas através do Sistema Eletrônico do Serviço de Informação ao Cidadão (e-sic)].

MINISTÉRIO DA CIDADANIA. Dados referentes ao Programa de Aquisição de Alimentos no Brasil. Brasília: MC, 2020. [Informações obtidas através do Sistema Eletrônico do Serviço de Informação ao Cidadão (e-sic)].

RAFFESTIN, Claude. Por uma geografia do poder. São Paulo: Ática, 1993.

SAQUET, Marcos Aurélio. Por uma Geografia das Territorialidades e das Temporalidades: uma concepção multidimensional voltada para a cooperação e para o desenvolvimento territorial. 2 Ed. Rio de Janeiro: Consequência, 2015. 164p.

SARON, F. de A.; NEVES NETO, C. de C.; HESPANHOL, A. N. As dificuldades de implementação dos programas de apoio à agricultura familiar no Brasil. Boletim de Geografia, Maringá, v. 35, n. 1, p. 1-16, 2017.

SILVA, M. G.; SILVA, S. P. Para além do acesso: Uma análise da relação entre mercados institucionais e empreendimentos de economia solidária no meio rural. Economia solidária e políticas públicas. Ipea, p. 87-93, nov. 2011. Disponível em: <http://repositorio.ipea.gov.br/bitstream/11058/3951/1/bmt49_econ04_paraalem.pdf >. Acesso em: 23 jan. 2021.

SILVA, Sandro Pereira. Avanços e Limites na Implementação de Políticas Públicas Nacionais sob a Abordagem Territorial no Brasil. In: Texto para discussão. Rio de Janeiro: IPEA, 2013.

SOUSA, Igor Breno Barbosa de. Programa Nacional de Alimentação Escolar: uma análise de dados sobre a estrutura, dinâmica e acesso no município de São Luís - MA de 2014 a 2018. São Luís, 2020. 174 f. Dissertação (Mestrado) - Curso de Desenvolvimento Socioespacial e Regional, Universidade Estadual do Maranhão, 2020.

SOUZA, Marcelo Lopes de. O território: sobre o espaço e poder, autonomia e desenvolvimento. In: CASTRO, Iná et al (Orgs). Geografia: conceitos e temas. Rio de janeiro: Bertrand Brasil, 1995. (p. 77-116). 
TOMAZINI, Carla Guerra,; LEITE, Cristiane Kerches da Silva. Programa Fome Zero e o paradigma da segurança alimentar: ascensão e queda de uma coalizão?. Revista de Sociologia Política, v. 24, n. 58, p. 13-30, jun. 2016.

VELOSO, Fernando. Redes locais e mercados institucionais de compra da agricultura familiar nos municípios de Adamantina, Paulicéia e Tupi Paulista (SP). Tese (Doutorado em Geografia). Universidade Estadual Paulista, Faculdade de Ciências e Tecnologia. Presidente Prudente: UESP, 2017.

Artigo recebido em 22-08-2018 Artigo aceito para publicação em 18-12-2020 